\title{
The PASS-Q: The Perceived Available Support in Sport Questionnaire
}

\author{
Paul Freeman, ${ }^{1}$ Pete Coffee, ${ }^{2}$ and Tim Rees ${ }^{1}$ \\ ${ }^{1}$ University of Exeter; ${ }^{2}$ Staffordshire University
}

\begin{abstract}
This article provides initial evidence for the construct validity of the Perceived Available Support in Sport Questionnaire (PASS-Q), which assesses emotional, esteem, informational, and tangible support. In Study 1, confirmatory factor analyses provided evidence for a four-dimension factor structure. Correlations supported hypothesized relationships between the PASS-Q dimensions and the Social Support Survey questions (Richman, Rosenfeld, \& Hardy, 1993). In Study 2 , the four-dimension factor structure was supported in an independent sample. Further, higher levels of perceived available emotional, esteem, informational, and tangible support were associated with higher levels of self-confidence and lower levels of burnout. Researchers are encouraged to use the PASS-Q to examine the effects of perceived available support in sport contexts.
\end{abstract}

Keywords: burnout, confirmatory factor analysis, self-confidence, social support, sport psychology

Social support has become recognized as an important resource for athletes and has been linked with the etiology of and recovery from injury, youth sport participation, burnout, self-confidence, and performance (for reviews, see Bianco \& Eklund, 2001; Holt \& Hoar, 2006; Rees, 2007). With the increase in studies examining social support in sport, the conceptualization and measurement of social support has become more diverse. For example, the term social support has encompassed both structural and functional aspects of interpersonal relationships, which have both been assessed in terms of quantity and satisfaction (for reviews, see Cohen, Gottlieb, \& Underwood, 2000; Holt \& Hoar, 2006). Structural aspects of social support refer to the existence of and interconnections between social ties. Functional aspects refer to the particular functions served by interpersonal relationships. Functional support may be divided into perceived available support and support actually received (Wills \& Shinar, 2000). Perceived available support refers to one's potential access to social support and is a support recipient's subjective judgment that friends, family, team-mates, and coaches would provide

Paul Freeman is with the School of Sport and Health Sciences, University of Exeter, St Luke's Campus, Exeter, United Kingdom. Pete Coffee is with Centre for Sport, Health, and Exercise Research, Staffordshire University, Stoke-on-Trent, United Kingdom. Tim Rees is with the School of Sport and Health Sciences, University of Exeter, St Luke's Campus, Exeter, United Kingdom. 
assistance if needed. Received support reflects the specific helping actions provided by friends, family, team-mates, and coaches, usually during a specific time frame. The different support constructs often have only low to moderate intercorrelations and may have different relationships with outcome variables (Barrera, 1986; Uchino, 2009). Researchers (e.g., Holt \& Hoar, 2006) have, therefore, argued that authors need to be clear in their conceptualization and measurement of social support. The purpose of the current study was to develop a sport-specific measure of perceived available support ${ }^{1}$ and provide initial evidence of its factor structure and reliability.

Concerns have been raised over the diversity of measures used to assess support and the lack of evidence regarding the psychometric properties of the various measures used in both sport (Holt \& Hoar, 2006) and general social psychology (Haber, Cohen, Lucas, \& Baltes, 2007; Vaux, 1992). For example, Winemiller, Mitchell, Sutcliff, and Cline (1993) found that in early social support research $61.1 \%$ of studies employed novel measures of support. Petrie and Falkstein (1998) highlighted that in the sport injury literature the Social Support Questionnaire, the Social Support Inventory, the People in My Life Inventory, and a modified version of the Support Functions Questionnaire had all been used to assess social support. Other social support measures used in sport psychology research include the Social Support Survey (SSS), the Interpersonal Support Evaluation List, and novel measures of support designed by researchers specifically for their studies (e.g., Rees $\&$ Hardy, 2004). One possible reason for the diversity of measures used to assess social support in sport may be the lack of a validated, sport-specific measure of support. Indeed, a number of researchers have noted the need to develop sportspecific measures of support (e.g., Holt \& Hoar, 2006; Petrie \& Falkstein, 1998). The development of measures that accurately assess specific support constructs will help to answer theoretically important questions, such as which types of support are beneficial and under what conditions (Cohen et al., 2000).

In sport, perceived available support has been associated with beneficial effects on self-confidence (Rees \& Freeman, 2007), processes underpinning performance (Rees, Ingledew, \& Hardy, 1999), performance outcome (Freeman \& Rees, 2009), and vulnerability to injury (Smith, Smoll, \& Ptacek, 1990). A number of the perceived available support measures used in sport psychology research were originally developed to assess support in general social psychology. Concerns have been raised regarding the content validity of such measures in sport because they assess general everyday support issues and do not account for the support issues that might be of specific relevance to high level sportspeople (Rees et al., 1999). Rees and Hardy (2000) found that, in addition to support with everyday issues, athletes required unique forms of support to help with sport-specific demands, such as selection issues, fitness concerns, and problems in training and competition. A recommendation in the social support literature is that measures of social support should be relevant to the target population and the situational context in which they are used (Bianco \& Eklund, 2001; House \& Kahn, 1985; Wills \& Shinar, 2000). Given the problems highlighted with using measures of support originally designed in general social psychology, researchers (e.g., Rees \& Hardy, 2004) have developed measures of perceived available support specifically for their studies. Although the construction of novel support measures for specific studies does address calls for support measures to be relevant to the situational context in which they are used, it may hinder the synthesis and comparison of research 
findings (Holt \& Hoar, 2006; Vaux, 1992; Winemiller et al., 1993). For example, it is difficult to ascertain whether the results observed are due to properties of idiosyncratic measures, theoretical support constructs, and/or the context in which the study was conducted.

An important issue to consider in the development of a measure is whether perceived available support should be conceived as a unidimensional or multidimensional construct. Multidimensional measures have conceptual advantages because viewing social support as a unidimensional construct may result in the differential impact of specific support functions being obscured (Cutrona \& Russell, 1990; Uchino, 2009; Wills \& Shinar, 2000). Although different multidimensional models of functional support have been proposed, Cutrona and Russell (1990) noted that the models appear to converge on emotional, esteem, informational, and tangible dimensions of support. These four dimensions are congruent with those found in sport by Rees and Hardy (2000), who conducted interviews with high-level athletes about their social support experiences. Emotional support refers to others being there for comfort and security, leading to a person feeling loved and cared for. Esteem support refers to others bolstering a person's sense of competence or self-esteem. Informational support refers to others providing advice or guidance. Tangible support refers to others providing concrete instrumental assistance (Cutrona \& Russell, 1990).

In light of the preceding discussion, this paper presents two studies that report the development and initial validation of a sport-specific measure of perceived available support: The Perceived Available Support in Sport Questionnaire (PASSQ). The PASS-Q is designed to be used in all sporting contexts, measures the availability of support if needed, and assesses four dimensions: emotional, esteem, informational, and tangible support.

\section{Study 1}

Researchers have noted that there is a need to develop sport-specific measures of support (e.g., Petrie \& Falkstein, 1998) if there are to be advances in the theoretical understanding of social support in sport (Holt \& Hoar, 2006). The purpose of Study 1 was to develop a sport-specific measure of perceived available support and provide initial evidence for its factor structure. It was hypothesized that a good model fit would be found for a 16-item, four-factor model of perceived available support, assessing the dimensions of emotional, esteem, informational, and tangible support. The use of multi-item scales is important and may have a number of advantages over single-item measures. For example, multi-item measures are less prone to measurement error and permit the inclusion of a range of behaviors that constitute each support dimension.

Concurrent validity for the PASS-Q was examined by comparing responses to the PASS-Q with responses to the SSS. Although the SSS was developed as a clinical assessment tool in the context of social work (Richman, Rosenfeld, \& Hardy, 1993) and not designed for the sporting context, the SSS has been used in sport psychology research. The SSS assesses eight types of social support: emotional support, listening support, emotional challenge, task appreciation, task challenge, reality confirmation, tangible assistance, and personal assistance. For each type of support, there are four questions: the number of providers of that 
support, satisfaction with that support, difficulty obtaining more of that support, and importance to one's overall well being of that support. Number of providers reflects a structural element of support, whereas the other three questions examine perceptions of functional elements of support. It was hypothesized that there would be significant relationships between the PASS-Q dimensions and SSS questions reflecting perceptions of functional elements of support, but that these relationships would depend on the dimensions of support. Rees, Hardy, and Evans (2007) found that the SSS listening support and emotional support questions accounted for significant variance in perceived emotional support. Similarly, Rees et al. found that the SSS task challenge and task appreciation questions accounted for significant variance in perceived esteem support, and that the SSS personal assistance questions accounted for significant variance in perceived tangible support. In the current study, therefore, it was hypothesized that the PASS-Q emotional support dimension and the SSS emotional support and listening support questions focusing on satisfaction, difficulty, and importance would be positively correlated; the PASS-Q esteem support dimension and the SSS task appreciation and task challenge questions focusing on satisfaction, difficulty, and importance would be positively correlated; and the PASS-Q tangible support dimension and the SSS personal assistance questions focusing on satisfaction, difficulty, and importance would be positively correlated. It was further hypothesized that the remaining correlations between the PASS-Q dimensions and the SSS questions would be of lower magnitude.

\section{Method}

\section{Initial Scale Construction}

The items for the present questionnaire were derived from statements made by high-level athletes about their social support experiences in sport (Rees \& Hardy, 2000). Many of the items have been used in previous perceived available support measures designed for specific studies examining the influence of perceived available support on performance outcome (Freeman \& Rees, 2008) and performancerelated variables (Rees \& Hardy, 2004). The items were preceded by a generic stem that asked, "If needed, to what extent would someone ....," with participants responding on a 5-point Likert scale ranging from 0 (not at all) to 4 (extremely so). Higher values represented higher levels of perceived available support. This format is congruent with measures of perceived available support used in general social psychology (for a review, see Wills \& Shinar, 2000).

Before data collection, the 16 items were assessed by nine independent judges (mean age 23.6 years, $S D=1.9$ ), who had all completed postgraduate modules detailing social support theory and quantitative research methods. The nine judges competed in a range of team $(n=6)$ and individual $(n=3)$ sports at club $(n=5)$, county $(n=3)$, and national $(n=1)$ level standard. The judges were initially required to read each item, then circle the social support dimension to which they felt the item belonged (Dunn, Bouffard, \& Rogers, 1999). For all 16 items, at least eight of the judges correctly assigned them to their respective dimensions. The judges also scrutinized the items for their relevance to athletes across a range of sports and competitive levels; all items were deemed relevant and appropriate. 


\section{Participants}

Participants were 180 (92 female, 88 male; mean age $19.4, S D=1.2$ years) sport and health science undergraduates at a university in the southwest of England. Participants competed in a variety of team $(n=125)$ and individual $(n=55)$ sports and had competed for a mean of $9.0(S D=3.9)$ years. The performance level of the participants comprised recreational $(n=12)$, club $(n=82)$, county $(n=57)$, national $(n=17)$, and international $(n=12)$ standard.

\section{Procedures}

The study was approved by an institutional ethics review committee, and participants provided informed consent. Participants completed the PASS-Q, the SSS, and a measure of social desirability in a lecture theater. The presentation of measures was systematically rotated to minimize order effects. One hundred and nineteen participants (mean age $19.4, S D=1.0$ year) from the original sample completed the PASS-Q on a second occasion, one week later.

\section{Other Measures}

The Social Support Survey. The present study focused on emotional support, listening support, task appreciation, task challenge, and personal assistance; Rees et al. (2007) found that these types of social support assessed by the SSS were related to perceived emotional, esteem, and tangible support assessed by a novel sportspecific measure constructed for their study. Within the SSS, emotional support refers to providing comfort and caring. Listening support refers to listening without giving advice or being judgmental. Task appreciation refers to acknowledging effort and expressing appreciation. Task challenge refers to challenging, stretching, and motivating. Personal assistance refers to providing services and help. Participants listed the initials of all individuals who provide them with that support and the initials were summed to provide a score for number of providers. Satisfaction (very dissatisfied-very satisfied), difficulty (very difficult-very easy), and importance (very unimportant-very important) were rated on 5-point Likert scales.

Social Desirability. Participants completed the 13-item version of the MarloweCrowne Social Desirability Scale (Reynolds, 1982). Participants rated whether 13 statements concerning personal attitudes and traits were true or false for them personally. Sample items included "I sometimes feel resentful when I don't get my way" and "I am always courteous, even to people who are disagreeable." Negatively phrased items were reverse scored and the responses were summed to create a total score. Higher scores represented more socially desirable behaviors.

\section{Analyses}

The data were screened for outliers, missing values, and indices of non-normality. The factor structure of the PASS-Q was tested using confirmatory factor analysis (CFA) with LISREL 8.30 (Jöreskog \& Sörbom, 1996). Maximum likelihood estimation was employed. The sequential model testing approach, as recommended by Jöreskog (1993), was employed and involved three stages. First, tests of separate single-factor 
models corresponding to individual perceived available support dimensions were performed, the purpose of which was to assess the convergent validity of the items making up each dimension. The overall goodness of fit of the models, the completely standardized factor loadings (loadings with values for $z$ above 1.96 were considered significant), the standardized residuals (values above 2 and below -2 were considered large), and the modification indices for the covariances between measurement errors (values above 7 were considered large) were examined (Jöreskog \& Sörbom, 1996). Second, tests of two-factor models were conducted by combining each pair of support dimensions. Examining the two-factor models helped to identify ambiguous items and investigate the discriminant validity of the dimensions. Modification indices were examined to determine if improvements in fit could be expected if items were freed to cross-load on another factor. The $95 \%$ confidence intervals $( \pm 1.96 \mathrm{SE})$ around the correlations between dimensions were also examined. A confidence interval including 1.0 would suggest that the factors were perfectly correlated and therefore lacked discriminant validity. All factors were then included in a four-factor model.

The primary focus was on the first-order, four-factor model that reflected emotional, esteem, informational, and tangible dimensions of support. As recommended in the structural equation modeling literature (e.g., Jackson, Gillaspy, \& Purc-Stephenson, 2009), alternative models were also examined. As it has been argued that perceived available support may be a unidimensional construct, a model examined a first-order, one-factor model. Further, the correlations between social support dimensions have often been found to be moderate to high, and it has been demonstrated in CFA with the Interpersonal Support Evaluation List that such correlations may be accounted for by the introduction of a higher-order factor (Brookings \& Bolton, 1988). In another model, therefore, we examined a four-factor model with a single higher-order factor.

Following evidence of univariate and multivariate non-normality (Mardia's normalized multivariate coefficient $=14.27$ ), the goodness of fit of all models was tested using the Satorra-Bentler chi-square statistic (SB $\left.\chi^{2}\right)$ and its ratio with the degrees of freedom. Further, we also examined the root mean square error of approximation (RMSEA) and its associated $p$-value (for RMSEA <.05), the standardized root mean square residual (SRMR), the comparative fit index (CFI), and the non-normed fit index (NNFI). These fit indices included measures from three different classes (absolute fit, absolute fit with penalty function, and incremental/ comparative fit) (Hu \& Bentler, 1999; Jöreskog, 1993). The SB $\chi^{2}$ statistic was used as a subjective index of fit (Jöreskog \& Sörbom, 1996), and a value for SB $\chi^{2}$ to degrees of freedom less than 2 was interpreted as a good initial indicator of fit. The recommendations for fit of $\mathrm{Hu}$ and Bentler are values for SRMR close to .08 , RMSEA close to .06, and CFI and NNFI close to $.95 .^{2}$ To compare the fit of competing models, the difference in CFI and the Satorra-Bentler scaled chi-square difference test (Satorra \& Bentler, 2001) were evaluated.

In addition to examining the factor structure, additional analyses were conducted to further assess the psychometric properties of the PASS-Q. Cronbach's alpha internal reliability coefficients, composite reliability, ${ }^{3}$ test-retest reliability, and correlations between the PASS-Q dimensions and social desirability scores were calculated. Correlations between the PASS-Q dimensions and SSS questions were examined to assess concurrent validity. Fifteen correlations were hypothesized to be significant, and the remaining correlations were hypothesized to be of lower 
magnitude. The proportion of the remaining correlations that were above and below the mean of the 15 hypothesized correlations was examined using a $\chi^{2}$ analysis. An alpha level of .05 was used for all statistical tests.

\section{Results}

\section{First-Order, Four-Factor Model}

The fit statistics and factor loadings at the single-factor stage are shown in Table 1. All four dimensions of support had good model fits. All the SB $\chi^{2}$ to degrees of freedom ratios were below 2, RMSEA values were .00 to .03 and were all nonsignificant, SRMR values were .01 to .02, NNFI values were .99-1.03, and CFI values were all 1.00 .

The fit statistics at the two-factor stage are shown in Table 2 along with the correlations between the factors. All the SB $\chi^{2}$ to degrees of freedom ratios were below 2, RMSEA values were .02 to .06 and were all nonsignificant, SRMR values were .04 to .06 , NNFI were .95 to .99 , and CFI values were .97 to .99 . Overall, the fit indices were indicative of good model fits (Hu \& Bentler, 1999). The 95\% confidence interval around the two-factor intercorrelations ranged from .26 to .93.

The fit statistics at the full four-factor stage are shown in Table 2 and the measurement error variances and completely standardized factor loadings are shown in Table 3. The descriptive statistics, reliability statistics, and correlations between factors are shown in Table 4. At the full four-factor model stage, the SB $\chi^{2}$ to degrees of freedom ratio was below 2, the RMSEA was .05 and nonsignificant, the SRMR was .06, the NNFI was .93, and the CFI was .94. These values are indicative of a reasonable fit (Hu \& Bentler, 1999). Cronbach's alpha internal reliability coefficients for the four dimensions ranged from .68 to .87 , composite reliabilities ranged from .69 to .87 , and test-retest reliabilities ranged from .73 to .84 . The correlations between the perceived available support dimensions ranged from moderate $(r=.40, p<.05)$ to high $(r=.84, p<.05)$.

\section{Alternative Models}

The first-order, one-factor model had a poor model fit. The SB $\chi^{2}$ to degrees of freedom ratio $\left(\mathrm{SB} \chi^{2}(104)=491.31, p<.01\right)$, the $\operatorname{RMSEA}(.14, p<.01)$, and the SRMR (.10) were all high. The NNFI (.72) and the CFI (.76) were both low. The model with one higher-order factor had a reasonable model fit. The SB $\chi^{2}$ to degrees of freedom ratio was below $2\left(\operatorname{SB} \chi^{2}(100)=185.52, p<.01\right)$, the RMSEA was .07 albeit significant $(p=.02)$, the SRMR was .08 , the NNFI was .89 , and the CFI was .91. The difference in CFI $(\Delta C F I=.03)$ and the Satorra-Bentler scaled chi-square difference test $\left(\chi^{2}(2)=35.37, p<.05\right)$, however, suggested that the fit of the first-order, four-factor model (our original model) was significantly better than the higher-order factor model.

\section{Relationship With Social Desirability}

All four PASS-Q dimensions were not significantly correlated with the social desirability ratings ( $r \mathrm{~s}-.12$ to $.03, p s>.05$ ) suggesting that the PASS-Q is not associated with social desirability bias. 


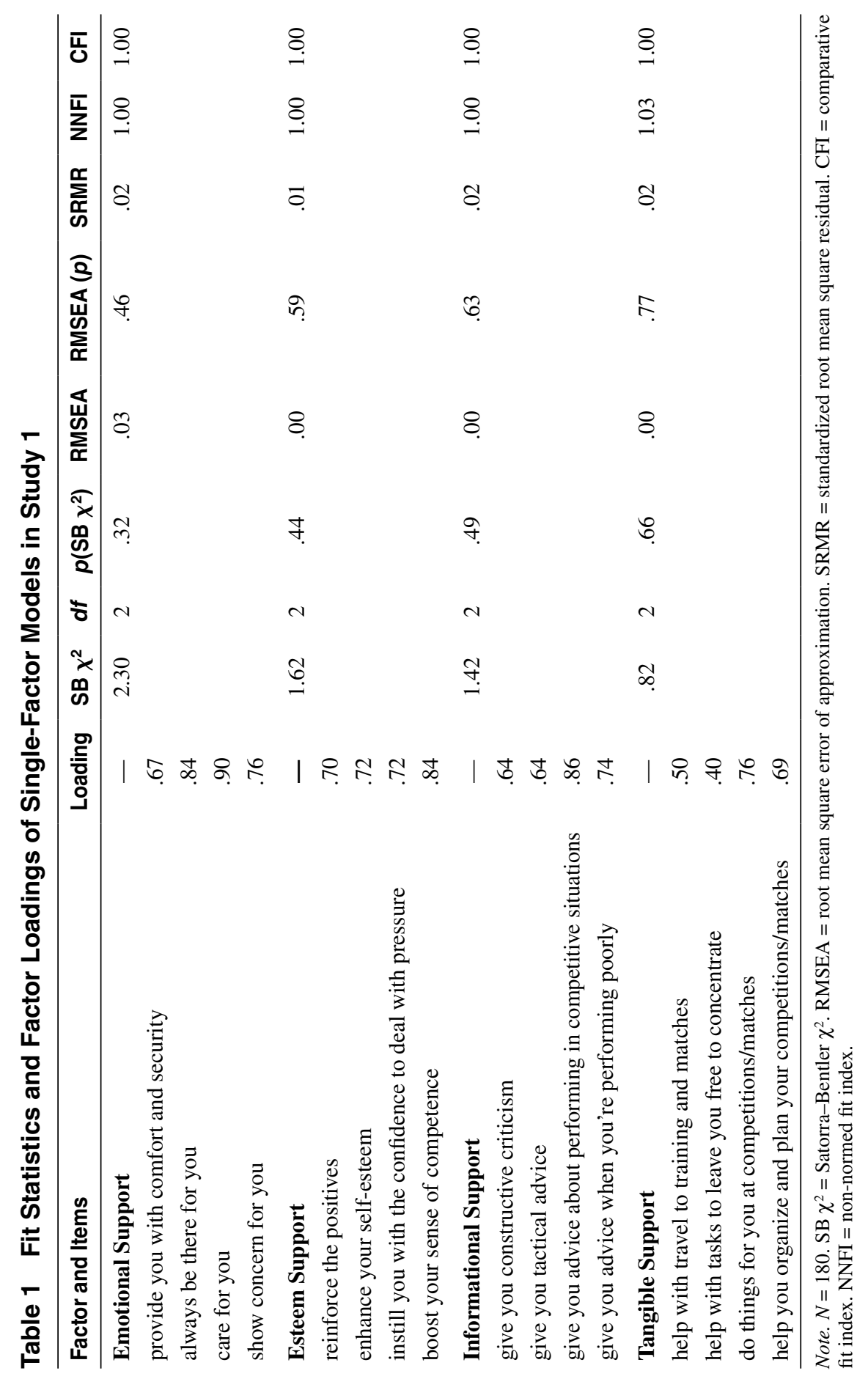




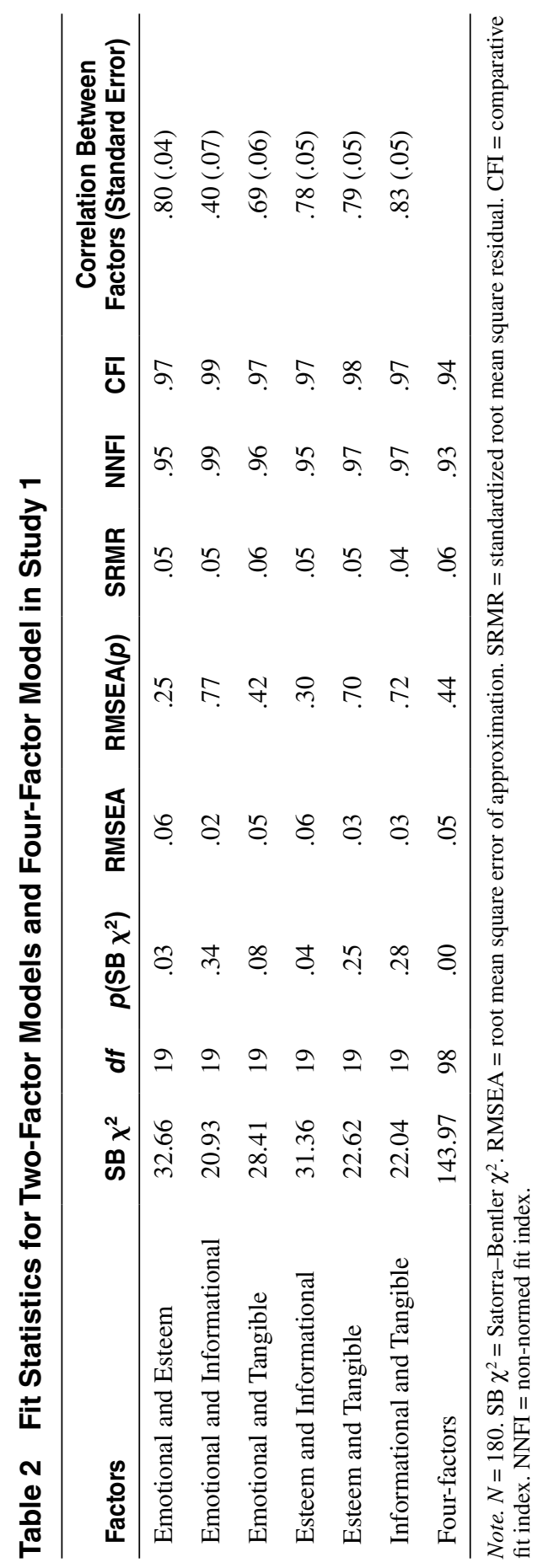




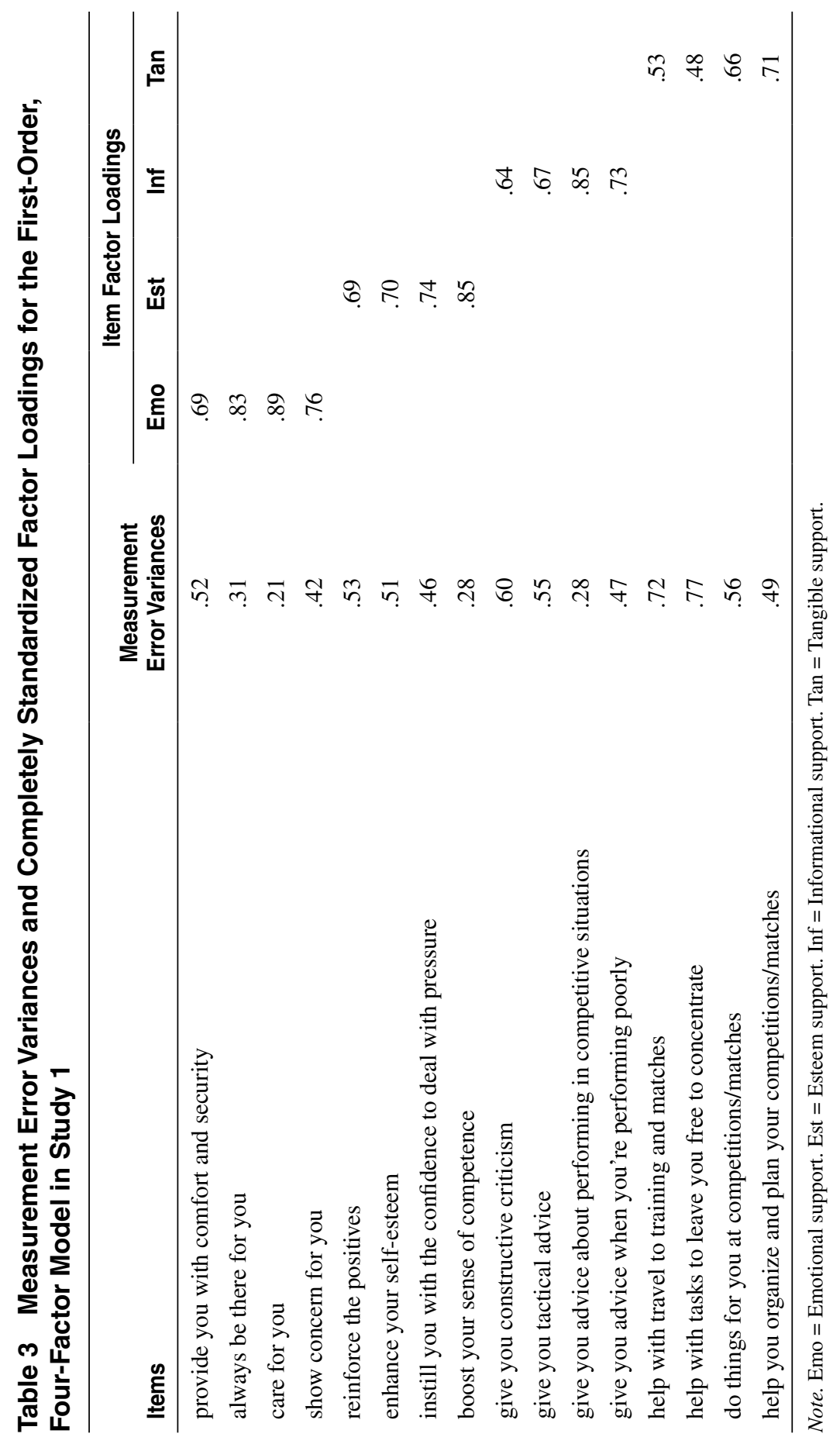


Table 4 Descriptive Statistics, Reliability Statistics, Factor-Factor Correlations of First-Order, Four-Factor Model in Study 1

\begin{tabular}{lccccccc}
\hline Factor & $\boldsymbol{M}(\boldsymbol{S D})$ & $\boldsymbol{\rho}_{\mathbf{c}}$ & $\boldsymbol{\alpha}$ & Test-retest & Factor-factor correlations \\
\hline Emotional & $2.40(.90)$ & .87 & .87 & .73 & & \\
Esteem & $2.55(.71)$ & .83 & .83 & .84 & $.79^{* *}$ & & \\
Informational & $2.74(.71)$ & .81 & .81 & .78 & $.40^{* *}$ & $.77^{* *}$ & \\
Tangible & $2.35(.80)$ & .69 & .68 & .73 & $.69^{* *}$ & $.79^{* *}$ & $.84^{* *}$ \\
\hline
\end{tabular}

Note. $N=180 . \rho_{\mathrm{c}}=$ composite reliability. $* p<.05, * * p<.01$.

\section{Relationships With SSS Questions}

To provide evidence for the concurrent validity of the PASS-Q, the correlations between the PASS-Q dimensions and SSS questions were examined. The PASS-Q emotional support dimension was significantly correlated $(r s .15$ to $.33, p s<.05)$ with all the SSS emotional support and listening support questions focusing on satisfaction, difficulty, and importance. The PASS-Q esteem support dimension was significantly correlated ( $r s .18$ to $.48, p s<.05)$ with all the SSS task appreciation and task challenge questions focusing on satisfaction, difficulty, and importance. The PASS-Q tangible support dimension was significantly correlated ( $r \mathrm{~s} .26$ to $.33, p s<.05$ ) with the SSS personal assistance questions focusing on satisfaction, difficulty, and importance. In summary, all 15 correlations that were hypothesized to be significant were supported; the mean value of these correlations was $r=.27$. Only 16 of the remaining correlations were greater than .27 ( $r \mathrm{~s}=.28$ to $.41, p \mathrm{~s}$ $<.05$ ), whereas 49 were less than .27 ( $r \mathrm{~s}=.07$ to $.26, p s=.32$ to .00$)$; a $\chi^{2}$ analysis revealed that the proportion of the correlations that were below .27 was significantly different than might be expected due to chance, $\chi^{2}(1)=16.76, p<.05$.

\section{Discussion}

The findings of Study 1 provide support for the first-order, four-factor structure of the PASS-Q. At the full four-factor stage, the factor loadings ranged from .53 to .89 except for one item. The factor loading of the tangible item "help with tasks to leave you free to concentrate" was .48. Although low, the loading was significant $(z=5.79, p<.05)$ and above the lower level of acceptable factor loadings (Snook \& Gorsuch, 1989); consequently, the item was retained. The correlations between the four factors ranged from .40 to .84 . Cohen and Wills (1985) noted that although social support may be broken down into specific dimensions conceptually, in naturalistic settings the dimensions are not usually independent. Brookings and Bolton (1988) argued that high correlations between support dimensions may be accounted for by the introduction of a higher-order factor. In the current study, the difference in CFI and a Satorra-Bentler scaled chi-square difference test provided evidence in favor of a first-order, four-factor model, in place of a model including a higher-order factor. 
The results also provide support for the concurrent validity of the PASS-Q. All the hypotheses that proposed significant positive correlations between PASS-Q dimensions and SSS questions were supported. A $\chi^{2}$ analysis supported the hypothesis that the remaining relationships would generally be of lower magnitude. A number of the remaining relationships were significant. Significant correlations have often been found between dimensions within a social support measure (e.g., Brookings \& Bolton, 1988), and so similar patterns might be expected across measures. People who provide support are able to do so in several ways so an athlete who reports high levels of emotional support on the PASS-Q may, for example, also report high levels of task appreciation on the SSS. Finally, the PASS-Q dimensions were not correlated with social desirability and generally had acceptable Cronbach's alpha internal reliability coefficients, composite reliabilities, and test-retest reliability coefficients.

\section{Study 2}

One purpose of Study 2 was to examine the factor structure of the PASS-Q in a second sample of athletes. It was hypothesized that the good model fit found for the first-order, four-factor model in Study 1 would be replicated in a new sample. Further, House and Kahn (1985) argued that establishing the validity of a social support measure involves consideration of the relationships between the measure and outcomes of theoretical and empirical relevance. The beneficial effects of social support have been noted for self-confidence (Freeman \& Rees, 2010; Rees \& Freeman, 2007) and burnout (Brown, Prashantham, \& Abbott, 2003; Raedeke \& Smith, 2004). Theory and empirical evidence has highlighted that there are different models in which social support may be associated with outcomes. Bianco and Eklund (2001) suggested that perceived available support is primarily associated with outcomes via the main effect model, whereas received support is most commonly associated with stress-buffering effects. In Study 2, therefore, we examined the direct relationships between PASS-Q dimensions and self-confidence and burnout. Following the findings of Freeman and Rees (2010), it was hypothesized that all four PASS-Q dimensions would be significantly correlated with self-confidence, with higher levels of support associated with higher levels of self-confidence. It was also hypothesized that all four PASS-Q dimensions would be significantly correlated with burnout, with higher levels of support associated with lower levels of burnout. Further, congruent with the prediction of Cutrona and Russell (1990) that esteem support would be the most effective dimension in achievement contexts, it was hypothesized that the PASS-Q esteem support dimension would be the primary predictor of self-confidence and burnout.

\section{Method}

\section{Participants}

Participants were 145 (68 female, 77 male; mean age 21.0, $S D=2.7$ years) competitive athletes. Participants competed in a variety of team $(n=112)$ and individual $(n=$ $33)$ sports and had competed for a mean of $11.9(S D=3.8)$ years. The performance 
level of the participants ranged from club $(n=69)$, county $(n=55)$, national $(n=$ $10)$, to international $(n=11)$ standard.

\section{Procedures}

The study was approved by an institutional ethics review committee, and participants provided informed consent. Participants were recruited at training sessions one week before a competition/match. Data were collected at two time points. At Time 1 (one week before a competition/match), participants completed the PASSQ. On the day before the competition/match, participants completed measures of self-confidence in relation to the upcoming competition/match, and burnout.

\section{Measures}

Perceived Available Support. The PASS-Q developed in Study 1 was used in the current study. No modifications were made to any of the items, the generic stem that preceded items, or response options.

Self-Confidence. Self-confidence was assessed using the scale from the revised version of the Competitive State Anxiety Inventory-2 (CSAI-2R; Cox, Martens, \& Russell, 2003). The self-confidence scale in the CSAI-2R has five items, and participants responded to statements about how confident they felt about their upcoming competition/match on a 4-point Likert scale ranging from 0 (not at all) to 3 (very much so). Sample items included "I'm confident I can meet the challenge" and "I'm confident about performing well." Cronbach's alpha internal reliability coefficient for the scale in the current study was .92 .

Burnout. Burnout was assessed using the Athlete Burnout Questionnaire (ABQ; Raedeke \& Smith, 2001). The ABQ has three subscales: emotional/physical exhaustion, reduced sense of personal accomplishment, and sport devaluation. There are 15 items (five items per subscale), with participants responding on a 5-point Likert scale ranging from 0 (almost never) to 4 (almost always). Example items include "I feel physically worn out from sport" (emotional/physical exhaustion), "I am not achieving much in sport" (reduced sense of personal accomplishment), and "I have negative feelings toward sport" (sport devaluation). Raedeke and Smith provided evidence for the construct and structural validity of the ABQ. In the current study, Cronbach's alpha internal reliability coefficients ranged from .78 to .92 .

\section{Analyses}

The data were screened for outliers, missing values, and indices of non-normality. The factor structure of the PASS-Q was tested using CFA with maximum likelihood estimation. Following evidence of univariate and multivariate non-normality (Mardia's normalized multivariate coefficient $=5.21$ ), we used the same measures of model fit reported in Study 1. Pearson's correlation coefficients were calculated to determine the relationships between the four PASS-Q dimensions and selfconfidence and burnout. Forced entry regression analyses were also used to examine the overall effects of the four PASS-Q dimensions on self-confidence and burnout. An alpha level of .05 was used for all statistical tests. 


\section{Results}

Confirmatory factor analysis of the four-factor model using the data in the current study revealed a good model fit. The SB $\chi^{2}$ to degrees of freedom ratio was below $2\left(\mathrm{SB} \chi^{2}(98)=120.56, p>.05\right)$, the RMSEA was low (.04) with a nonsignificant test for close fit $(p>.05)$, the SRMR was low (.04), and the CFI (.98) and the NNFI (.98) were high. Factor loadings were between .66 and .86, and were all significant. Cronbach's alpha internal reliability coefficients for the four factors ranged from .79 to .89 , and composite reliabilities ranged from .82 to .89 .

The results of the correlation analyses are shown in Table 5. All four PASS-Q dimensions were significantly correlated with self-confidence ( $r \mathrm{~s}=.37$ to $.44, p \mathrm{~s}<$ .01 ), with higher levels of support associated with higher levels of self-confidence. All four PASS-Q dimensions significantly were significantly correlated with all three ABQ subscales $(r \mathrm{~s}=-.29$ to $-.38, p \mathrm{~s}<.01$ ), with higher levels of support associated with lower levels of burnout.

\section{Table 5 Correlation Analyses: Pearson's Correlation Coefficients Between PASS-Q Dimensions and Self-Confidence and Burnout}

\begin{tabular}{lcccc}
\hline & Emo & Est & Inf & Tan \\
\hline Self-confidence & $.41^{* *}$ & $.44 * *$ & $.37 * *$ & $.41^{* *}$ \\
Reduced sense of accomplishment & $-.31^{* *}$ & $-.38^{* *}$ & $-.30^{* *}$ & $-.34 * *$ \\
Sport devaluation & $-.29 * *$ & $-.31^{* *}$ & $-.35^{* *}$ & $-.27 * *$ \\
Emotional/physical exhaustion & $-.33^{* *}$ & $-.34 * *$ & $-.38^{* *}$ & $-.29 * *$ \\
\hline
\end{tabular}

Note. $N=145 . * p<.05, * * p<.01$. Emo = Emotional support. Est = Esteem support. Inf = Informational support. Tan $=$ Tangible support.

The results of the forced entry regression analyses are shown in Table 6. Collectively, the four PASS-Q dimensions significantly predicted self-confidence $\left(R^{2}=.22, p<.01\right)$, reduced sense of accomplishment $\left(R^{2}=.15, p<.01\right)$, sport devaluation $\left(R^{2}=.13, p<.01\right)$, and emotional and physical exhaustion $\left(R^{2}=.16\right.$, $p<.01)$. The effects on self-confidence and reduced sense of accomplishment were primarily attributable to esteem support $(b=.20, p=.09$ and $b=-.23, p=$ .07 , respectively). The effects on sport devaluation and emotional and physical exhaustion were primarily attributable to informational support $(b=-.27, p<.05$ and $b=-.29, p<.05$, respectively).

\section{Discussion}

The results provide partial evidence to support the study hypotheses. First, further evidence was provided to support the four-dimension factor structure of the PASS-Q with an independent sample. Second, the findings demonstrate that available emotional, esteem, informational, and tangible support were significantly 


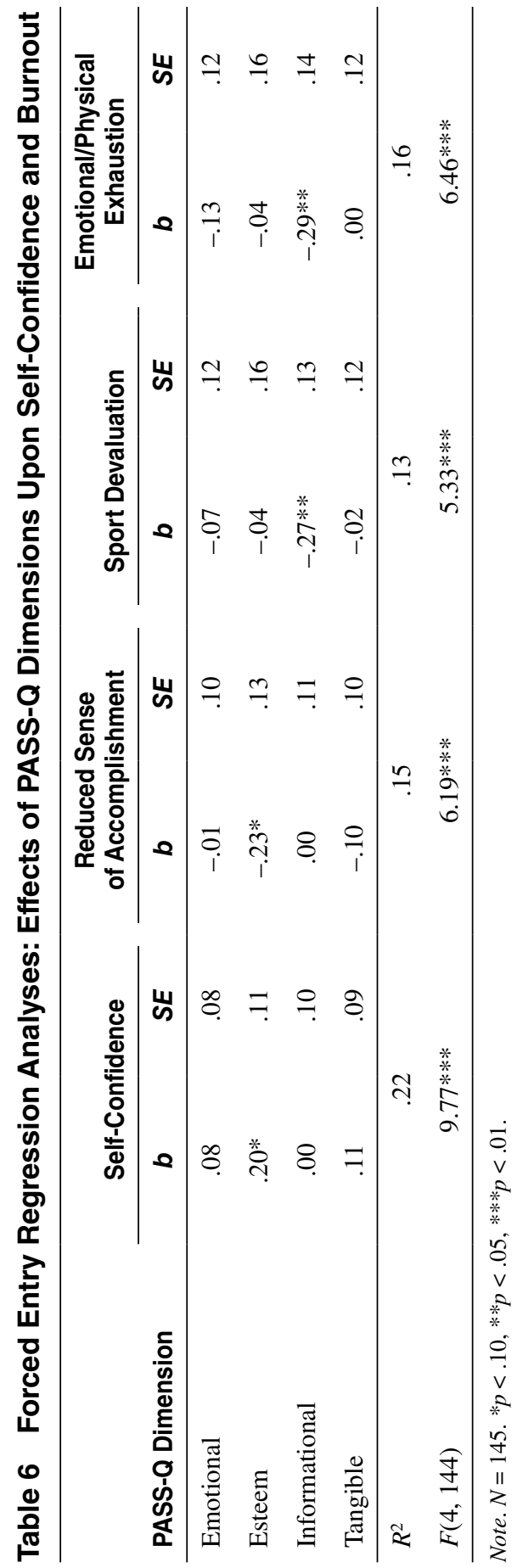


correlated with self-confidence and burnout. Previous research has also noted the link between support and both self-confidence (Rees \& Freeman, 2007) and burnout (Brown et al., 2003). The results of the regression analyses only partially supported the prediction of Cutrona and Russell (1990) that esteem support is the key dimension in achievement contexts. Although the effects on self-confidence and reduced sense of accomplishment were primarily attributable to esteem support, the effects on sport devaluation and emotional and physical exhaustion were primarily attributable to informational support. These findings highlight the benefit of using multidimensional measures of support such as the PASS-Q. Indeed without such measures, researchers are unable to identify differential impacts of specific support dimensions. Overall, the findings of Study 2 provide evidence for the structural and predictive validity of the PASS-Q.

\section{General Discussion}

Despite social support becomingly increasingly recognized as an important resource for athletes, research in the area has been limited by the lack of a context-specific, psychometrically sound measure of perceived available support (Holt \& Hoar, 2006). The present article addressed this issue and reported the development of a sport-specific measure of perceived available support. Study 1 found a reasonable fit for the first-order, four-factor model of the PASS-Q. Study 2 reported a good fit for the first-order, four-factor model of the PASS-Q in an independent sample. In short, the findings from both studies support the factor structure of the PASS-Q.

The multidimensional measure of perceived available support presented in this article will allow researchers to examine theoretically interesting questions. For example, testing the optimal matching model (Cutrona \& Russell, 1990) requires a multidimensional measure of support. The PASS-Q could help understand which dimensions are most beneficial for various outcomes and contexts. The differential effects of perceived support dimensions have been noted on a range of outcomes including stress (Varvel et al., 2007), quality of life (Drageset et al., 2009), and recovery from surgery (King, Reis, Porter, \& Norsen, 1993). The dimensions may also operate through different mechanisms. Freeman and Rees (2009) found that perceived esteem support was most associated with performance outcome, and that it operated through challenge, threat, and situational control appraisals. The other three dimensions of support were not associated with performance or appraisal variables. Through using the PASS-Q to help identify the dimensions of perceived support that are most beneficial and understand how they operate, research will enhance both theory and the development of effective theory-led support interventions (Thoits, 1995).

The correlations between the four PASS-Q dimensions in Study 1 were moderate to high ( $r \mathrm{~s}=.40$ to .84 ). Similar correlations have been noted with other measures of perceived available support. For example, correlations between the dimensions of the general population version of the Interpersonal Support Evaluation List have ranged from .31 to .81 (Cohen, Mermelstein, Kamarck, \& Hoberman, 1985). Wills and Shinar (2000) noted that although several dimensions may have been defined theoretically, it is common for empirical studies to find significant correlations among dimensions. People who provide support are able to do so in several ways, so dimensions are not necessarily mutually exclusive (Brookings \& Bolton, 1988; 
Wills \& Shinar, 2000). Study 1, therefore, examined whether alternative factor structures for the PASS-Q were tenable. A poor fit was found for a first-order, onefactor model. Despite the possible existence of a higher-order factor, the difference in CFI and a Satorra-Bentler scaled chi-square difference test in Study 1 provided support for the retention of the first-order, four-factor model.

Other psychometric properties of the PASS-Q examined in both studies were generally acceptable and congruent with the hypotheses and existing empirical evidence. Study 1 provided initial evidence of the concurrent validity of the PASS-Q. The hypotheses that proposed significant relationships between PASS-Q dimensions and SSS questions were supported. Rees et al. (2007), similarly, found that the SSS and perceived emotional, esteem, and tangible support shared significant variance. A $\chi^{2}$ analysis supported the hypothesis that the remaining correlations between PASS-Q dimensions and SSS questions would generally be of lower magnitude. Further, like the SSS (Richman et al., 1993), the Interpersonal Support Evaluation List (Cohen et al., 1985), and the Social Support Questionnaire (Sarason, Levine, Basham, \& Sarason, 1983), all four PASS-Q dimensions were not significantly correlated with ratings of social desirability. With the exception of the tangible support dimension in Study 1, Cronbach's alpha internal reliability coefficients and the composite reliabilities all exceeded .70 . The test-retest reliability coefficients of all four dimensions were also acceptable.

Study 2 addressed the recommendation of House and Kahn (1985) to examine the relationships between the social support measure and outcomes of theoretical and empirical relevance. Researchers have argued that social support is an important source of self-confidence (Vealey, Hayashi, Garner-Holman, \& Giacobbi, 1998), and perceived available support has been found to be positively associated with self-confidence (Rees \& Freeman, 2007). Study 2 found significant relationships between all four PASS-Q dimensions and self-confidence. All four PASS-Q dimensions were also significantly related to burnout. The negative relationship between social support and burnout is congruent with previous research in both sport (Raedeke \& Smith, 2004) and work contexts (Brown et al., 2003). The findings, however, were not completely consistent with the suggestion of Cutrona and Russell (1990) that esteem support is the most effective dimension in achievement contexts. The forced entry regression analyses found that dimensions of perceived available support may have differential effects; the effects on self-confidence and reduced sense of accomplishment were primarily attributable to esteem support, and the effects on sport devaluation and emotional and physical exhaustion were primarily attributable to informational support. Similarly, differential effects of perceived support dimensions have been noted on various outcomes in general social psychology (e.g., Drageset et al., 2009; King et al., 1993; Varvel et al., 2007). Future research could use the PASS-Q to examine the effect of all four dimensions on other cognitive, emotional, and behavioral outcomes in sporting contexts.

The PASS-Q asked participants to rate their overall perceptions of available support without specifying the potential provider(s) of this support. Bianco (2001) highlighted that it may be important to understand the effects of support from specific providers. Wills and Shinar (2000), however, noted that measures which assess overall support from a range of providers have successfully predicted important outcomes, so measures do not necessarily have to identify the providers of support. Further, it should be emphasized that the PASS-Q only provides an assessment of 
perceived available support and not other social support constructs such as structural aspects of social networks or functional support received in the recent past. The instructions of the PASS-Q could be rephrased to assess received support. Similar approaches have been adopted in general social psychology. For example, Vaux, Riedel, and Stewart (1987) suggested that although the Social Support Behaviors Scale was designed to assess available support, with modifications to the wording it can, and has been, used to assess received support. Any revised form of the PASS-Q, of course, should undergo psychometric testing.

A potential limitation in both Study 1 and 2 is that the sample sizes were generally low for conducting confirmatory factor analysis (Tabachnick \& Fidell, 2007). The low sample size may have affected the power of the analysis and the stability of the solution. Owing to the sample size, we did not test for factorial invariance across gender; this could be examined in future research. It should be noted, however, that any possible gender differences might have influenced the results found in the present studies. We did examine whether standardizing within gender before analysis altered the results, but found no evidence to support this in either Study 1 or $2 .{ }^{4}$ Finally, the correlations could also have been inflated by common method variance and/or positive affectivity.

In summary, this article has provided initial evidence for the factor structure of the PASS-Q. The development of measures that accurately assess support availability will help to answer theoretically important questions (Cohen et al., 2000). Further, the PASS-Q addresses the recommendations that measures of social support should be relevant to the target population and situational context in which they are used (Bianco \& Eklund, 2001; House \& Kahn, 1985; Wills \& Shinar, 2000). In short, we hope that the PASS-Q will be used by researchers to investigate the effects of perceived available support in sporting contexts. The development and consistent use of such a measure is likely to contribute to the synthesis and comparison of research findings (Holt \& Hoar, 2006; Vaux, 1992; Winemiller et al., 1993).

\section{Notes}

1. The creation and use of measures that assess specific support constructs is important because measures are not interchangeable (Bianco \& Eklund, 2001; Lakey \& Cohen, 2000; Wills \& Shinar, 2000). Lakey and Cohen outlined that different theoretical perspectives have guided social support research and each perspective is associated with specific types of support constructs.

2 . In the current study, these values were used as guides rather than absolute cut-off values. Marsh, Hau, and Wen (2004) raised concerns regarding the widespread incorporation of such stringent guidelines and using them as if they were golden rules. Indeed, Hu and Bentler (1999) never intended their guidelines to be interpreted as universal golden rules or absolute cutoff values.

3. Coefficient alpha assumes parallel measures and represents a lower bound estimate of internal reliability (Bollen, 1989; Miller, 1995). In CFA, the items/factors are weighted unequally based on their reliability, with relatively higher weights for items with greater reliability. A better estimate can be gained using the composite reliability formula. Composite reliability $\rho_{\mathrm{c}}$ is defined as follows (adapted from Fornell \& Larcker, 1981):

$$
\rho_{\mathrm{c}}=\frac{\left(\sum L_{i}\right)^{2}}{\left(\sum L_{i}\right)^{2}+\sum \operatorname{Var}\left(E_{i}\right)}
$$


where $L_{i}$ represents the standardized factor loadings for that factor and $\operatorname{Var}\left(E_{i}\right)$ is the error variance associated with the individual indicator variables (items).

4. We would like to thank an anonymous reviewer for this suggestion. Full details of these additional analyses are available from the first author.

\section{References}

Barrera, M., Jr. (1986). Distinctions between social support concepts, measures, and models. American Journal of Community Psychology, 14, 413-445.

Bianco, T. (2001). Social support and recovery from sport injury: Elite skiers share their experiences. Research Quarterly for Exercise and Sport, 72, 376-388.

Bianco, T., \& Eklund, R.C. (2001). Conceptual considerations for social support research in sport and exercise settings: The case of sport injury. Journal of Sport \& Exercise Psychology, 23, 85-107.

Bollen, K.A. (1989). Structural equations with latent variables. New York: Wiley.

Brookings, J.B., \& Bolton, B. (1988). Confirmatory factor analysis of the Interpersonal Support Evaluation List. American Journal of Community Psychology, 16, 137-147.

Brown, N.C., Prashantham, B.J., \& Abbott, M. (2003). Personality, social support and burnout among human service professionals in India. Journal of Community \& Applied Social Psychology, 13, 320-324.

Cohen, S., Gottlieb, B.H., \& Underwood, L.G. (2000). Social relationships and health. In S. Cohen, L.G. Underwood, \& B.H. Gottlieb (Eds.), Social support measurement and intervention: A guide for health and social scientists (pp. 3-25). New York: Oxford University Press.

Cohen, S., Mermelstein, R., Kamarck, T., \& Hoberman, H. (1985). Measuring the functional components of social support. In I.G. Sarason \& B.R. Sarason (Eds.), Social support: Theory, research, and applications (pp. 73-94). Dordrecht: Martinus Nijhoff.

Cohen, S., \& Wills, T.A. (1985). Stress, social support, and the buffering hypothesis. Psychological Bulletin, 98, 310-357.

Cox, R.H., Martens, M.P., \& Russell, W.D. (2003). Measuring anxiety in athletics: The revised Competitive State Anxiety Inventory-2. Journal of Sport \& Exercise Psychology, 25, 519-533.

Cutrona, C.E., \& Russell, D.W. (1990). Type of social support and specific stress: Toward a theory of optimal matching. In B.R. Sarason, I.G. Sarason, \& G.R. Pierce (Eds.), Social support: An interactional view (pp. 319-366). New York: Wiley.

Drageset, J., Eide, G.E., Nygaard, H.A., Bondevik, M., Nortvedt, M.W., \& Natvig, G.K. (2009). The impact of social support and sense of coherence on health-related quality of life among nursing home residents-A questionnaire survey in Bergen, Norway. International Journal of Nursing Studies, 46, 66-76.

Dunn, G.H., Bouffard, M., \& Rogers, W.T. (1999). Assessing item content-relevance in sport psychology scale-construction research: Issues and recommendations. Measurement in Physical Education and Exercise Science, 3, 15-36.

Fornell, C., \& Larcker, D.G. (1981). Evaluating structural equation models with unobservable variables and measurement error. JMR, Journal of Marketing Research, 18, 39-50.

Freeman, P., \& Rees, T. (2008). The effects of perceived and received support upon objective performance outcome. European Journal of Sport Science, 8, 359-368.

Freeman, P., \& Rees, T. (2009). How does perceived support lead to better performance? An examination of potential mechanisms. Journal of Applied Sport Psychology, 21, 429-441.

Freeman, P., \& Rees, T. (2010). Perceived social support from teammates: Direct and stressbuffering effects on self-confidence. European Journal of Sport Science, 10, 59-67. 
Haber, M., Cohen, J., Lucas, T., \& Baltes, B. (2007). The relationship between self-reported received and perceived social support. American Journal of Community Psychology, $39,133-144$.

Holt, N.L., \& Hoar, S.D. (2006). The multidimensional construct of social support. In S. Hanton \& S.D. Mellalieu (Eds.), Literature reviews in sport psychology (pp. 199-225). Hauppauge, NY: Nova Science.

House, J.S., \& Kahn, R.L. (1985). Measures and concepts of social support. In S. Cohen \& S.L. Syme (Eds.), Social support and health (pp. 83-108). New York: Academic.

Hu, L., \& Bentler, P.M. (1999). Cutoff criteria for fit indexes in covariance structure analysis: Conventional criteria versus new alternatives. Structural Equation Modeling, 6, 1-55.

Jackson, D.L., Gillaspy, J.A., \& Purc-Stephenson, R. (2009). Reporting practices in confirmatory factor analysis: An overview and some recommendations. Psychological Methods, 14, 6-23.

Jöreskog, K.G. (1993). Testing structural equation models. In K.A. Bollen \& J.S. Long (Eds.), Testing structural equation models (pp. 294-316). Newbury Park, CA: Sage.

Jöreskog, K.G., \& Sörbom, D. (1996). LISREL 8 user's reference guide. Chicago, IL: Scientific Software International.

King, K.B., Reis, H.T., Porter, L.A., \& Norsen, L.H. (1993). Social support and long-term recovery from coronary artery surgery: Effects on patients and spouses. Health Psychology, 12, 56-63.

Lakey, B., \& Cohen, S. (2000). Social support measurement and theory. In S. Cohen, L.G. Underwood, \& B.H. Gottlieb (Eds.), Social support measurement and intervention: A guide for health and social scientists (pp. 29-52). New York: Oxford University Press.

Marsh, H.W., Hau, K.T., \& Wen, Z. (2004). In search of golden rules: Comment on hypothesis-testing approaches to setting cutoff values for fit indexes and dangers in overgeneralizing Hu and Bentler's (1999) findings. Structural Equation Modeling, 11, 320-341.

Miller, M. B. (1995). Coefficient alpha: A basic introduction from the perspectives of classical test theory and structural equation modeling. Structural Equation Modeling, 2, 255-273.

Petrie, T.A., \& Falkstein, D.L. (1998). Methodological, measurement, and statistical issues in research on sport injury prediction. Journal of Applied Sport Psychology, 10, 26-45.

Raedeke, T.D., \& Smith, A.L. (2001). Coping resources and athlete burnout: An examination of stress mediated and moderation hypotheses. Journal of Sport \& Exercise Psychology, 26, 525-541.

Raedeke, T.D., \& Smith, A.L. (2004). Development and preliminary validation of an athlete burnout measure. Journal of Sport \& Exercise Psychology, 23, 281-306.

Rees, T. (2007). Influence of social support on athletes. In S. Jowett \& D. Lavallee (Eds.), Social psychology in sport (pp. 223-231). Champaign, IL: Human Kinetics.

Rees, T., \& Freeman, P. (2007). The effects of perceived and received support on selfconfidence. Journal of Sports Sciences, 25, 1057-1065.

Rees, T., \& Hardy, L. (2000). An investigation of the social support experiences of high-level sport performers. The Sport Psychologist, 14, 327-347.

Rees, T., \& Hardy, L. (2004). Matching social support with stressors: Effects on factors underlying performance in tennis. Psychology of Sport and Exercise, 5, 319-337.

Rees, T., Hardy, L., \& Evans, L. (2007). Construct validity of the social support survey in sport. Psychology of Sport and Exercise, 8, 355-368.

Rees, T., Ingledew, D.K., \& Hardy, L. (1999). Social support dimensions and components of performance in tennis. Journal of Sports Sciences, 17, 421-429.

Reynolds, W.M. (1982). Development of reliable and valid short forms of the MarloweCrowne Social Desirability Scale. Journal of Clinical Psychology, 38, 119-125.

Richman, J.M., Rosenfeld, L.B., \& Hardy, C.J. (1993). The Social Support Survey: A validation of a clinical measure of the social support process. Research on Social Work Practice, 3, 23-33. 
Sarason, I.G., Levine, H.M., Basham, R.B., \& Sarason, B.R. (1983). Assessing social support: The Social Support Questionnaire. Journal of Personality and Social Psychology, 44, 127-139.

Satorra, A., \& Bentler, P.M. (2001). A scaled chi-square test statistic for moment structure analysis. Psychometrika, 66, 507-514.

Smith, R.E., Smoll, F.E., \& Ptacek, J.T. (1990). Conjunctive moderator variables in vulnerability and resiliency research: Life stress, social support, coping skills, and adolescent sport injuries. Journal of Personality and Social Psychology, 58, 360-370.

Snook, S.C., \& Gorsuch, R.L. (1989). Component analysis versus common factor analysis: A Monte Carlo study. Psychological Bulletin, 106, 148-154.

Tabachnick, B.G., \& Fidell, L.S. (2007). Using multivariate statistics. Boston: Allyn \& Bacon.

Thoits, P.A. (1995). Stress, coping, and social support processes: Where are we? What next? Journal of Health and Social Behavior (Extra Issue), 53-79.

Uchino, B.N. (2009). Understanding the links between social support and physical health. Perspectives on Psychological Science, 4, 236-255.

Varvel, S.J., He, Y., Shannon, J.K., Tager, D., Bledman, R.A., Chaichanasakul, A., et al. (2007). Multidimensional, threshold effects of social support in firefighters: Is more support invariably better? Journal of Counseling Psychology, 54, 458-465.

Vaux, A. (1992). Assessment of social support. In H.O.F. Veiel \& U. Baumann (Eds.), The meaning and measurement of social support (pp. 193-216). New York: Hemisphere.

Vaux, A., Riedel, S., \& Stewart, D. (1987). Modes of social support: The Social Support Behaviors (SS-B) Scale. American Journal of Community Psychology, 15, $209-237$.

Vealey, R.S., Hayashi, S.W., Garner-Holman, M., \& Giacobbi, P. (1998). Sources of sportconfidence: Conceptualization and instrument development. Journal of Sport \& Exercise Psychology, 20, 54-80.

Wills, T.A., \& Shinar, O. (2000). Measuring perceived and received social support. In S. Cohen, L.G. Underwood, \& B.H. Gottlieb (Eds.), Social support measurement and intervention: A guide for health and social scientists (pp. 86-135). New York: Oxford University Press.

Winemiller, D.R., Mitchell, M.E., Sutcliff, J., \& Cline, D.J. (1993). Measurement strategies in social support: A descriptive review of the literature. Journal of Clinical Psychology, 49, 638-648.

Manuscript received: February 18, 2010

Revision accepted: October 2, 2010 